\title{
OnabotulinumtoxinA for the treatment of idiopathic overactive bladder is effective and safe for repeated use
}

\author{
Kevin Carlson, $M D^{1,2 ;}$; Andrea Civitarese, $B S c^{1}$; Richard Baverstock, $M D^{1,2}$ \\ 'vesia [Alberta Bladder Centre]; ' 2 Department of Surgery, Cumming School of Medicine, University of Calgary; Calgary, AB, Canada
}

Cite as: Can Urol Assoc J 2017;11 (5):E179-83. http://dx.doi.org/10.5489/cuai.4194

Published online May 9, 2017

\section{Abstract}

Introduction: The objective of this study was to compare efficacy and safety outcomes between patients receiving onabotulinumtoxinA (OnabotA) for the first time and those receiving a repeat injection.

Methods: Data collected before and after OnabotA injection were extracted from a clinical registry. Patients were classified into either first or repeat injection subgroups. Efficacy was measured by the change in use of oral bladder medications, the number of voids per day or night, the frequency of urinary incontinence (UI) episodes, and patient-reported outcomes. Safety was measured by the number of self-reported complications. Differences in safety measures between the subgroups were tested.

Results: The analysis included complete data from 81 patients; 30 (37\%) receiving OnabotA for the first time, 51 (63\%) receiving a repeat injection. Both subgroups reported significant reductions in the use of anticholinergics, more tolerable bladder symptoms, and improvements in patient-reported outcomes. Dry rates were similarly high in both groups (50\% and $43 \%$, respectively). There were no statistically significant differences between the subgroups in terms of their safety outcomes.

Conclusions: OnabotA is equally as efficacious and safe for patients with overactive bladder receiving a repeat injection as it is for those receiving their first injection.

\section{Introduction}

The use of onabotulinumtoxinA (OnabotA) as a third-line treatment for idiopathic overactive bladder (OAB) is supported in amended clinical guidelines from the America Urological Association ${ }^{1}$ and the European Association of Urology. ${ }^{2}$ These guidelines are based on high-quality, randomized controlled trials (RCTs) that have been published in the recent past. ${ }^{1-5}$

Meta-analyses of these RCTs report significant improvements in OAB-related outcomes, including incontinence, urodynamics, and patient-reported outcomes (PROs), along with few adverse events. ${ }^{6-8}$ One such review outlines that $60-65 \%$ of patients injected at a $100 \mathrm{U}$ dose reported improvements in urgency incontinence, symptom scores, and quality of life. These patients significantly improved as compared to a placebo group. ${ }^{9}$ Adverse events, such as incomplete emptying and urinary tract infection (UTI), are reported in some cases, with UTI reported in $2-32 \%$ of patients treated with OnabotA in a review by Yokoyama et al. ${ }^{10}$ Otherwise, adverse events are either mild or transient in nature.

While evidence for the de novo use of OnabotA to treat $\mathrm{OAB}$ is compelling, evidence supporting repeated use is less established. The few studies that have formally evaluated efficacy and safety of repeated use of OnabotA to treat $\mathrm{OAB}$ report similar results. Both the de novo and repeateduse subgroups experience significant differences in terms of their pre-/post-injection: frequency, urgency, or incontinence; PROs; and occurrence of adverse events. ${ }^{6-8,11}$ The limitations of these studies lie in their small sample sizes (often only women) and, while the pre-/post-injection differences may be significant, they do not test if the changes experienced by the subgroups are significantly different. This latter limitation is important to better understand the effect of repeatedly using OnabotA to treat OAB.

The overall objective of this study is to compare midterm safety and efficacy outcomes between patients receiving OnabotA for the first time and those receiving a repeat injection. To address this, we developed a clinical registry of patients receiving OnabotA for OAB in a "real-world" setting from one of three urologists. Standard guideline-based care for $\mathrm{OAB}$ was provided for all patients in the registry. The results from this study will give urologists more confidence in using OnabotA long-term to treat refractory OAB.

\section{Methods}

This study sampled patients with idiopathic OAB treated with OnabotA at our high-volume referral centre for lower urinary tract symptoms. Patients with OAB presenting at the clinic for either de novo or repeat intravesical OnabotA through usual clinical pathways (including failed behavioural modification 
and ineffective response and/or intolerance to medications) were asked if they would allow their data added to the registry. This convenience sample was recruited from May 2014 to June 2015.

Patients who were interested went through a formal informed consent process with a research assistant (RA). Patients who were under the age of 18 , had a history of neurological disease, or who were unwilling or unable to provide informed consent or complete PROs were excluded. This study was approved by the Health Research Ethics Board of Alberta.

Data was collected for the registry at three time points by a single RA:

1. Immediately after completing informed consent. Participants answered questions about their urinary symptoms and bladder management. PROs were also collected using validated condition-specific instruments: the International Consultation on Incontinence Questionnaire-Urinary Incontinence (ICIQ-UI), Urogenital Distress Inventory (UDI-6), and Patient Perception of Bladder Condition (PPBC). The participant's chart was retrospectively reviewed using the clinic's electronic medical record system to extract additional health history.

2. At the time of the injection procedure. Immediately after injection, the urologist recorded appearance of the bladder, number of units injected and volume of dilution, number of injection sites, and type of cystoscope and needle.

3. At three-month followup, PROs were completed and information regarding symptom severity, bladder management, and complications were collected.

Efficacy was conceptually defined as improvements in participants' sense of urgency. It was operationally defined by use of oral OAB medications, number of voids per day or night, frequency of urinary incontinence (UI) episodes, dry rates, and PROs. OnabotA injections were considered to be equally efficacious between the de novo and repeated-use subgroups if there were no significant differences between their pre-/post-injection changes to the use of anticholinergics, number of voids per day or night, frequency of UI episodes, and PRO global scores three months after injection.

Safety was conceptually defined as number of adverse events related to OnabotA toxicity. It was operationally defined by the number of complications reported by participants, including: UTIs, hematuria, and need for those spontaneously voiding prior to injection to catheterize. OnabotA was considered equally safe between the de novo and repeated-use subgroups if there were no significant differences in these self-reports.

\section{Data analysis}

Data was extracted from the registry to conduct the analysis for this study. Descriptive statistics of demographic and medical history variables were used to characterize the sample. The frequency of specific bladder pharmacology and bladder management variables were calculated and compared before and after injections, noting any differences, with a $p$ value less than 0.05 as significant using the Wilcoxon signed-ranks test or paired t-test for matched pairs. To answer this study's research questions, participants were divided into two subgroups depending on whether they were receiving their first or repeated OnabotA injection for OAB. Differences in safety measures between the subgroups were tested using Fisher's exact test. This analysis was conducted in Stata 14 (StataCorp LP, College Station, TX, U.S).

\section{Results}

Eighty-one patients with $\mathrm{OAB}$ were identified from the registry for analysis. All of the patients had failed behavioural modifications and did not respond to or could not tolerate oral OAB drugs. The majority $(\mathrm{n}=70,86 \%)$ were female, and the mean age was 60.2 years, with a range of 26-85 years.

Thirty $(37 \%)$ participants received OnabotA for the first time; the remainder $(n=51,63 \%)$ were receiving a repeat injection. The average number of prior injections received by the latter group was 3.79, with a median of 3.00 (interquartile range [IQR] 2.00-5.00). The median number of days since their previous injection was 237 (range 79-1239; IQR 182-315).

As detailed in Table 1, there were no statistically significant differences between the first time and repeat-injection subgroups in terms of gender, age, or body mass index (BMI), nor were there any statistically significant differences between the two subgroups with respect to their bladder pharmacology and management.

The majority $(n=19 ; 63 \%)$ of first-time participants were injected with 100 units (U) OnabotA (range 100-200 U), while the majority $(n=31 ; 61 \%)$ of repeat injections were injected with $200 \mathrm{U}$ (range 100-200 U); these differences were statistically significant $(p=0.006)$. Injections were performed using either a rigid or flexible cystoscope, with either a Cook Williams needle (Cook Medical, Bloomington, IN, U.S) or Olympus needle (Olympus Corporation, Center Valley, PA, U.S), respectively. Participants in the repeat subgroup received significantly more injections compared to the first-time subgroup (mean 16.8 vs. $12.2 ; \mathrm{p}<0.001$ ). There were no significant differences in the self-reported pain scores between the two subgroups.

Table 2 details the change in efficacy for those participants receiving OnabotA for the first time. The proportional use of anticholinergics significantly decreased from baseline to three-months post-injection. Over $43 \%$ of participants were 


\begin{tabular}{|c|c|c|c|}
\hline & $\begin{array}{c}\text { First } \\
\text { injection } \\
(n=30)\end{array}$ & $\begin{array}{c}\text { Repeat } \\
\text { injection } \\
(n=51)\end{array}$ & $\begin{array}{c}\text { Fisher's } \\
\text { exact }\end{array}$ \\
\hline \multicolumn{4}{|l|}{ Participant characteristics } \\
\hline \multicolumn{4}{|l|}{ Sex } \\
\hline Male & 7 & 4 & \multirow[t]{2}{*}{$\mathrm{p}=0.70$} \\
\hline Female & 23 & 47 & \\
\hline $\begin{array}{l}\text { Age } \\
\text { (t-test for differences in mean } \\
\text { values) }\end{array}$ & 58.7 & 61.0 & $\begin{array}{l}t=-0.80 \\
p=0.42\end{array}$ \\
\hline $\begin{array}{l}\text { Body mass index } \\
\text { (t-test for differences in mean } \\
\text { values) }\end{array}$ & 28.6 & 27.3 & $\begin{array}{l}t=0.75 \\
p=0.46\end{array}$ \\
\hline \multicolumn{4}{|l|}{ Bladder management } \\
\hline \multicolumn{4}{|l|}{ Spontaneous voiding } \\
\hline No & 2 & 2 & \multirow{3}{*}{$\mathrm{p}=0.62$} \\
\hline Yes & 27 & 49 & \\
\hline Missing & 1 & & \\
\hline \multicolumn{4}{|c|}{ Indwelling or suprapubic catheter } \\
\hline No & 29 & 51 & \multirow{2}{*}{$\mathrm{p}=0.37$} \\
\hline Yes & 1 & 0 & \\
\hline \multicolumn{4}{|l|}{ Clean intermittent catheterization } \\
\hline No & 28 & 41 & \multirow{2}{*}{$\mathrm{p}=0.19$} \\
\hline Yes & 2 & 10 & \\
\hline \multicolumn{4}{|l|}{ Number of catheterizations/day } \\
\hline $1-7$ & 2 & 7 & \multirow{3}{*}{$\mathrm{p}=0.30$} \\
\hline $8+$ & 0 & 3 & \\
\hline Does not catheterize & 28 & 41 & \\
\hline
\end{tabular}

on an anticholinergic prior to their first OnabotA treatment; this proportion dropped to $16.7 \%$ three months post-injection. There was a significant reduction in bladder symptoms, including a proportional reduction in number of voids per day, nocturia events, and UI episodes. Twelve of 24 (50\%) previously incontinent patients reported being dry at followup. The total dry rate increased from $20 \%$ to $60 \%$. There were also significant changes to all PROs; scores for the UDI-6, $I C I Q$, and PPBC all significantly improved after injections.

The changes in efficacy measures for those receiving a repeat injection of OnabotA are provided in Table 3. Notably, a lesser proportion of patients at baseline were taking an anticholinergic compared to the first-time injection subgroup $(24 \%$ vs. $43 \%)$; however, a similar reduction was noted at the three-month followup, where $10 \%$ were taking one. This subgroup also experienced a significant reduction in bladder symptoms, with a proportional reduction in the number of voids per day and nocturia events. Sixteen of 37 (43\%) previously incontinent patients became dry by followup and overall dry rates improved from $27 \%$ to $59 \%$. PROs also improved to a similar degree compared to the first-injection group.

Results from the comparison of safety measures across subgroups are provided in Table 4 . Some differences were observed; however none of these differences were statisti-
Table 2. Self-reported efficacy measures from participants receiving their first injection of onaboulinumtoxin $A$

\begin{tabular}{lccc}
\hline $\mathbf{n = 3 0}$ & Baseline & $\begin{array}{c}\text { Three- } \\
\text { month } \\
\text { followup }\end{array}$ & $\begin{array}{c}\text { Wilcoxon } \\
\text { signed- } \\
\text { ranks test }\end{array}$ \\
\hline Pharmacological use & & & \\
\hline $\begin{array}{l}\text { Use of anticholinergics } \\
\text { No } \\
\text { Yes }\end{array}$ & 17 & 25 & $\mathrm{z}=2.53$ \\
$\mathrm{p}=0.01$
\end{tabular}

\section{Bladder symptoms}

Number of voids/day

$1-7$

8-10

$11+$

Does not void

Missing

Nocturia events/night

$\begin{array}{lllll}0 & 2 & 9 & \mathrm{z}=3.04\end{array}$

$1-3$

$20 \quad 21 \quad \mathrm{p}<0.01$

$4+$

80

Urinary incontinence episodes

None

1-2 per month

$6 \quad 18$

1-2 per week

3-6 per week

1 or more per day

$10 \quad 4$

$z=2.05$

$\mathrm{p}=0.04$

\begin{tabular}{|c|c|c|c|}
\hline Patient-reported outcomes & & & $\begin{array}{c}\text { Paired } \\
\text { t-test }\end{array}$ \\
\hline UDI-6 (mean score) & 50.5 & 28.3 & $\begin{array}{c}t=4.78 \\
p=0.0001\end{array}$ \\
\hline ICIQ (mean score) & 12.3 & 6.9 & $\begin{array}{c}t=5.38 \\
p<0.0001\end{array}$ \\
\hline $\begin{array}{l}\text { PPBC (item 3) } \\
\text { Does not cause me any } \\
\text { problems } \\
\text { Causes me some very minor } \\
\text { problems }\end{array}$ & & & \\
\hline $\begin{array}{l}\text { Causes me some minor } \\
\text { problems } \\
\text { Causes me some moderate } \\
\text { problems } \\
\text { Causes me severe problems } \\
\text { Causes me many severe } \\
\text { problems }\end{array}$ & 4.7 & 3.1 & $\begin{array}{c}t=6.33 \\
p<0.0001\end{array}$ \\
\hline
\end{tabular}

cally significant. Of those receiving OnabotA for the first time, $27 \%$ reported having a UTI, compared to $25 \%$ of those having a repeat injection. Only one patient from the repeatinjection group reported hematuria. More patients receiving OnabotA for the first time $(17 \%)$ reported having to selfcatheterize compared to the repeat-injection group (6\%).

Pearson correlation coefficients were used to compare UTIs and the need to self-catheterize (data not presented). For the de novo group, there was a weak negative correlation of $-0.07(p=0.72)$ that was not statistically significant. For the repeat-injection group, there was a positive correlation of $0.42(p<0.01)$ that was statistically significant. 


\begin{tabular}{|c|c|c|c|}
\hline$n=51$ & Baseline & $\begin{array}{l}\text { Three- } \\
\text { month } \\
\text { followup }\end{array}$ & $\begin{array}{l}\text { Wilcoxon } \\
\text { signed- } \\
\text { ranks test }\end{array}$ \\
\hline \multicolumn{4}{|l|}{ Pharmacological use } \\
\hline $\begin{array}{l}\text { Use of anticholinergics } \\
\text { No } \\
\text { Yes }\end{array}$ & $\begin{array}{l}39 \\
12\end{array}$ & $\begin{array}{c}46 \\
5\end{array}$ & $\begin{array}{l}z=2.65 \\
p=0.01\end{array}$ \\
\hline \multicolumn{4}{|l|}{ Bladder symptoms } \\
\hline $\begin{array}{l}\text { Number of voids/day } \\
1-7 \\
8-10 \\
11+ \\
\text { Does not void }\end{array}$ & $\begin{array}{c}9 \\
13 \\
27 \\
2\end{array}$ & $\begin{array}{l}28 \\
15 \\
4 \\
4\end{array}$ & $\begin{array}{c}z=4.82 \\
p<0.001\end{array}$ \\
\hline $\begin{array}{l}\text { Nocturia events/night } \\
0 \\
1-3 \\
4+\end{array}$ & $\begin{array}{c}3 \\
38 \\
10\end{array}$ & $\begin{array}{c}20 \\
31 \\
0\end{array}$ & $\begin{array}{c}z=4.29 \\
p<0.001\end{array}$ \\
\hline $\begin{array}{l}\text { Urinary incontinence episoc } \\
\text { None } \\
1-2 \text { per month } \\
1-2 \text { per week } \\
3-6 \text { per week } \\
1 \text { or more per day }\end{array}$ & $\begin{array}{l}14 \\
19 \\
7 \\
9 \\
2\end{array}$ & $\begin{array}{c}30 \\
7 \\
4 \\
6 \\
4\end{array}$ & $\begin{array}{l}z=1.28 \\
p=0.20\end{array}$ \\
\hline Patient-reported outcomes & & & $\begin{array}{c}\text { Paired } \\
\text { t-test }\end{array}$ \\
\hline UDI-6 (mean score) & 43.1 & 25.6 & $\begin{array}{c}t=5.49 \\
p<0.0001\end{array}$ \\
\hline ICIQ (mean score) & 8.9 & 4.9 & $\begin{array}{c}t=4.45 \\
p=0.0001\end{array}$ \\
\hline
\end{tabular}

PPBC

Does not cause me any

problems

Causes me some very minor

problems

Causes me some minor

problems

$\begin{array}{llc} & t=6.32 \\ & 2.6 & p<0.0001\end{array}$

Causes me some moderate

problems

Causes me severe problems

Causes me many severe

problems

ICIQ: International Consultation on Incontinence Questionnaire; PPBC: Patient Perception of Bladder Condition; UDI: Urogenital Distress Inventory.

\section{Discussion}

In this clinical registry of real-world patients with $\mathrm{OAB}$ treated with OnabotA, the midterm safety and efficacy outcomes between patients being injected for the first time and those receiving a repeated injection were assessed. Though the repeat-injection subgroup was larger, they shared similar characteristics in terms of bladder treatment and management. Both subgroups experienced a decrease in their use of anticholinergics, number voids per day, nocturia events, dry rates, and PROs. There were no significant differences observed between the two subgroups in self-reported UTIs,

\begin{tabular}{|c|c|c|c|}
\hline & $\begin{array}{l}\text { First injection } \\
\qquad(n=30)\end{array}$ & $\begin{array}{c}\text { Repeat injection } \\
(n=51)\end{array}$ & $\begin{array}{c}\text { Fisher's } \\
\text { exact }\end{array}$ \\
\hline \multicolumn{4}{|c|}{ Urinary tract infection } \\
\hline No & 22 & 38 & \multirow{2}{*}{$p=1.00$} \\
\hline Yes & 8 & 13 & \\
\hline \multicolumn{4}{|c|}{ Hematuria } \\
\hline No & 30 & 50 & \multirow{2}{*}{$p=1.00$} \\
\hline Yes & 0 & 1 & \\
\hline \multicolumn{4}{|c|}{$\begin{array}{l}\text { Need to initiate self- } \\
\text { catheterization }\end{array}$} \\
\hline No & 25 & 48 & \multirow[t]{2}{*}{$p=0.14$} \\
\hline Yes & 5 & 3 & \\
\hline
\end{tabular}

hematuria, or need to initiate self-catheterization. These results suggest that OnabotA remains equally as efficacious and safe for repeated injections to treat $O A B$ as it does for the first.

Reflecting the real-world nature of this study, and similar to other such studies, ${ }^{13}$ dosing for injections ranged from 100-200 U of OnabotA. While $100 \mathrm{U}$ is the current recommended dose, ${ }^{2}$ some patients in this study may have been initiated on $200 \mathrm{U}$ before results from phase 3 trials were published and before OnabotA received Health Canada approval for the treatment of OAB with UI. Alternatively, a subgroup of patients may have been escalated to higher dosages based on clinical response. Our current practice is to initiate treatment at $100 \mathrm{U}$ for all patients with idiopathic $\mathrm{OAB}$ undertaking their first injection.

The efficacy results in this real-world study differed from those reported in published phase 3 clinical trials by Nitti et $\mathrm{al}^{4}$ and Chapple et $\mathrm{al}^{12}$ Both of these reported a significant decrease in the mean frequency of daily UI episodes, ranging from $53.1-57.5 \%$. While the proportional changes in UI episodes for the de novo group were not significant in this study, an increased proportion reported being dry at the three-month followup, and among the cohort of patients incontinent at baseline, $50 \%$ became dry. A similar comparison can be made of the rates of nocturia. Both trials report a statistically significant decrease in the mean frequency of nocturia events, ranging from $20.2-25.1 \%$. The proportional differences observed in the de novo group in this study were not significant, but proportionally more reported having no episodes at the three-month followup. Both the phase 3 trials and this study observed significant improvements in PROs.

Statistically significant decreases in the use of anticholinergics at three-month post-injection were observed in both the de novo and repeat groups. There was an over $50 \%$ decrease in the proportional use of anticholinergics at three months post-injection. Clearly, however, in the realworld setting, a small proportion (e.g., $10 \%$ of our repeatinjection group) of patients will remain on oral medication in addition to their OnabotA injections, and depending on 
the timing of repeat injections, some patients may need to resume oral therapy to "bridge the gap" if symptoms return to a bothersome degree. Concomitant anticholinergic use may, in part, explain our high dry rates and also our higher clean intermittent catheterization $(\mathrm{CIC})$ rates, compared to phase 3 clinical trials.

Our safety results also differ from phase 3 clinical trials, ${ }^{4,12}$ but are in keeping with other real-world studies. ${ }^{13}$ Both phase 3 trials reported UTI as the most frequent adverse event, ranging from $15.5-20.4 \%$, which is lower than the $26.6 \%$ rate observed in the de novo group of this study, and the $35 \%$ rate reported by Osborn et al. These trials also reported rates of initiating self-catheterization of $6.1-6.9 \%$, compared to $16.7 \%$ of the de novo group in this study. The trial reported by Chapple et al observed 3.6\% of their trial arm had hematuria compared to $2 \%$ of the de novo group in this study. ${ }^{12}$

Our study is not without limitations. Firstly, it was not a clinical trial and participants were not randomized; therefore, there may be some systematic bias in terms of who returned for a repeat injection. However, within this limitation lies strength, insofar as the intent of the study was to represent patients treated in a real-world setting. We did not want to reproduce the strict inclusion/exclusion criteria used in clinical trials of OnabotA. Our results demonstrate that there may be differences in terms of safety and efficacy outcomes between clinical trial participants and patients treated in community-based urology. Secondly, participants did not undergo routine urodynamic testing or formal bladder diary collection at the three-month followup, which may provide more objective data regarding changes in OAB. The selfreported outcomes used in this study are those that are used to inform clinical decision-making with respect to the safety and efficacy of treatment for OAB. Despite these limitations, these results are generalizable to other urology clinics treating $\mathrm{OAB}$ with OnabotA.

\section{Conclusion}

OnabotA is as safe and efficacious for patients with $O A B$ receiving a repeat injection as it is for those receiving their first injection. The results from this study demonstrate that the magnitude of changes in safety and efficacy outcomes do not differ significantly as patients are repeatedly injected with OnabotA. Clinicians using this as an intervention for their $\mathrm{OAB}$ patients can be confident that patients will experience similar results, regardless of how many times they have been previously injected.

Competing interests: Dr. Carlson and Dr. Baverstock are advisors and speakers for Allergan. Ms. Civitarese reports no competing personal or financial interests. Allergan Canada Inc. provided an unrestricted research grant to the investigators to support this study.
Acknowledgements: The authors would like to acknowledge Dr. Bryce Weber, Dr. Darren Desantis, and Dr. Daniel Yanko for assisting in this study's data collection. Also deserving of acknowledgement is Dr. Trafford Crump, for his thorough review of the manuscript and suggestions for data analysis.

This paper has been peer-reviewed.

\section{References}

1. Denys P, Le Normand L, Ghout I, et al. Efficacy and safety of low doses of onabotulinumtoxinA for the treatment of refractory idiopathic overactive bladder: A multicentre, double-blind, randomized, placebo-controlled, dose-ranging study. Eur Urol 2012; 61:520-9. https://doi.org/10.1016/i.eururo.2011.10.028

2. Dmochowski R, Chapple C, Nitti VW, et al. Efficacy and safety of onabotulinumtoxina for idiopathic overactive bladder: A double-blind, placebo controlled, randomized, dose-ranging trial. J Urol 2010;184: 2416-22. https://doi.org/10.1016/i.juro.2010.08.021

3. Fowler $\mathrm{CJ}$, Auerbach $\mathrm{S}$, Ginsberg D, et al. OnabotulinumtoxinA improves health-related quality of life in patients with urinary incontinence due to idiopathic overactive bladder: A 36-week, double-blind, placebocontrolled, randomized, dose-ranging trial. Eur Urol 2012;62:148-57. https://doi.org/10.1016/j. eururo.2012.03.005

4. Nitti VW, Dmochowski R, Herschorn S, et al. OnabotulinumtoxinA for the treatment of patients with overactive bladder and urinary incontinence: Results of a phase 3 , randomized, placebo-controlled trial. J Urol 2013;189:2186-93. hitps://doi.org/10.1016/i.juro.2012.12.022

5. Rovner E, Kennelly M, Schulte-Baukloh H, et al. Urodynamic results and clinical outcomes with intradetrusor injections of onabotulinumtoxinA in a randomized, placebo-controlled, dose-finding study in idiopathic overactive bladder. Neurourol Urodyn 2011;30:556-62. https://doi.org/10.1002/nau.21021

6. Abeywickrama L, Arunkalaivanan A, Quinlan M. Repeated botulinum toxin type A (Dysport ${ }^{\circledR}$ ) injections for women with intractable detrusor overactivity: A prospective outcome study. Int Urogynecol J 2014;25:6015. https://doi.org/10.1007/s00192-013-2228-2

7. Dowson C, Watkins J, Khan MS, et al. Repeated botulinum toxin type A injections for refractory overactive bladder: Medium-term outcomes, safety profile, and discontinuation rates. Eur Urol 2012;61:834-9. htrps://doi.org/10.1016/i.eururo.2011.12.011

8. Granese R, Adile G, Gugliotta G, et al. Botox for idiopathic overactive bladder: Efficacy, duration, and safety. Effectiveness of subsequent injection. Arch Gynecol Obstet 2012;286:923-9. https://doi.org/10.1007/ s00404-012-2349-8

9. Cox L, Cameron AP. OnabotulinumtoxinA for the treatment of overactive bladder. Res Reports Urol 2014;4:79-89.

10. Yokoyama T, Chancellor MB, Oguma K, et al. Botulinum toxin type $A$ for the treatment of lower urinary tract disorders. Int J Urol 2012;19:202-15. https://doi.org/10.1111/j.1442-2042.2011.02946.x

11. Sahai A, Dowson C, Khan MS, et al. Repeated injections of botulinum toxin-A for idiopathic detrusor overactivity. Urology 2010;75:552-8. https://doi.org/10.1016/i.urology.2009.05.097

12. Chapple C, Sievert K-D, MacDiarmid S, et al. OnabotulinumtoxinA $100 \mathrm{U}$ significantly improves all idiopathic overactive bladder symptoms and quality of life in patients with overactive bladder and urinary incontinence: A randomized, double-blind, placebo-controlled trial. Eur Urol 2013;64:249-56. https://doi.org/10.1016/i.eururo.2013.04.001

13. Osborn DJ, Kaufman MR, Mock $S$, et al. Urinary retention rates after intravesical onabotulinumtoxinA injection for idiopathic overactive bladder in clinical practice and predictors of this outcome. Neurol Urodyn 2015;34:675-8. https://doi.org/10.1002/nau.22642

Correspondence: Dr. Richard Baverstock, Department of Surgery, Cumming School of Medicine, University of Calgary, Calgary, AB, Canada; richard.baverstock@ahs.ca 